\title{
The Development of Hindlimb Motor Activity Studied in the Isolated Spinal Cord of the Chick Embryo
}

\author{
Michael J. O'Donovan' ${ }^{1}$ and Lynn Landmesser ${ }^{2}$
}

'Department of Physiology and Biophysics, University of lowa, lowa City, lowa 52242, and 2Department of Physiology and Neurobiology, University of Connecticut, Storrs, Connecticut 06268

The development of hindlimb motor activity was studied in an isolated preparation of the chick spinal cord. The motor output from lumbosacral segments was characterized by recording the pattern of ventral root and muscle nerve discharge in 6-14-d-old embryos. In addition, the synaptic drive underlying motoneuron activity was monitored electrotonically from the ventral roots.

Spontaneous motor activity consisted of recurring episodes of cyclical motoneuron discharge. During development, both the number of cycles in each episode and the intensity of discharge in each cycle progressively increased. Monophasic, positive ventral root potentials accompanied each cycle of motoneuron discharge. Prior to the innervation of hindlimb muscles at stage 26 , ventral root discharge was barely detectable despite the presence of large ventral root potentiais. Following hindlimb muscle innervation, each cycle of activity was initiated by a brief, intense discharge that coincided with the rising phase of the ventral root potential. In embryos older than stage 30 , the initial discharge was followed, after a delay, by a more prolonged discharge. The duration of ventral root potentials was shortest in the stage 26 embryos, but was similar in embryos at stage 29 and older.

The developmental changes in the coordination of antagonist activity were documented by recording the pattern of discharge in sartorius (flexor) and caudilioflexorius (extensor) muscle nerves between stage 30 and stage 36. At stage 30 both sets of motoneurons were coactivated during the brief discharge that initiated each cycle. By stage 31 a second discharge occurred in each cycle. The second discharge was delayed in flexor, but not in extensor, motoneurons, which led to an alternating pattern of activity. Between stages 32 and 36 the precision of alternation improved because the onset of flexor and extensor activity became more synchronous.

Our results raise the possibility that muscle innervation may play a role in the maturation of motor activity or, alternatively, that motor activity may be involved in some aspect of muscle innervation. Developmental changes in motoneuron membrane properties may be involved in the ontogeny

\footnotetext{
Received Oct. 7, 1986; revised Apr. 3, 1987; accepted Apr. 24, 1987.

This work was supported by a grant from the National Science Foundation (BNS 8402838) to M.J.O'D. and by NIH Grant NS 19640 to L.L.

Correspondence should be addressed to Michael J. O'Donovan, M.D., Ph.D. Department of Physiology and Biophysics, Room 5-470 BSB, The University of Iowa, Iowa City, IA 52242.

Copyright (C) 1987 Society for Neuroscience $0270-6474 / 87 / 103256-09 \$ 02.00 / 0$
}

of activity patterns because the appearance of antagonist alternation was not accompanied by major changes in the form or time course of ventral root potentials.

Locomotion in vertebrates is believed to be generated by circuits of spinal interneurons called central pattern generators (see Grillner, 1981, for a review). At present it is not known how spinal networks produce the patterned motor output characteristic of locomotion. To address this question, a number of workers have turned to embryonic or neonatal preparations, which offer the potential advantage of anatomical and functional simplicity (Bekoff et al., 1975; Stehouwer and Farel, 1980, 1983; Kahn and Roberts, 1982; Soffe and Roberts, 1982; Landmesser and O'Donovan, 1984; O'Donovan, 1986a, 1987). In addition, embryonic preparations of the ncrvous system can be maintained in vitro, which greatly facilitates their experimental analysis (Stehouwer and Farel, 1980; Velumian, 1981; Kahn and Roberts, 1982; Landmesser and O'Donovan, 1984; O'Donovan, 1987). We have been studying the production of motor behavior in the chick embryo and have developed an isolated spinal cord preparation that generates spontaneous motor activity when maintained in vitro (Landmesser and O'Donovan, 1984). The chick promises to be a good model system for studying motor activity in higher vertebrates because its spinal cord organization is similar to that in mammals (Eide et al., 1982; Velumian, 1984; Okada and Oppenheim, 1985; O'Donovan, 1986a), and many of the basic aspects of chick neural development have been well characterized (for reviews, see Hamburger, 1976; Landmesser, 1976, 1980). We have previously used electromyography to show that antagonist hindlimb motoneurons alternate and synergists are coactive at stages $35-36$ both in ovo and in vitro (Landmesser and O'Donovan, 1984). The purpose of the present investigation was to document how this pattern of activity develops, using the isolated spinal cord preparation. Although the development of hindlimb motor activity has been analyzed previously in the chick using in ovo electromyography (Bekoff et al., 1975; Bekoff, 1976) and microelectrode recordings (Provine, 1972, 1973; Ripley and Provine, 1972), studies in intact embryos have technical limitations that preclude a cellular analysis of motor development. The isolated cord preparation is more accessible experimentally because it is stable enough for intra- and extracellular recording from spinal neurons (Velumian, 1981, 1985; O'Donovan, 1986a, b, 1987). The use of an isolated preparation provided 2 additional advantages over previous studies in ovo. First, the activity of identified moloneurons could be recorded from embryos younger than those that could feasibly be studied in ovo, and second, motoneuron excitatory drive could be monitored electrotonically from the 
ventral roots at several stages of development (O'Donovan, 1986b, 1987).

\section{Materials and Methods}

Experiments were performed on white Leghorn chickens maintained in a forced-draft incubator at $37^{\circ} \mathrm{C}$. Motor activity was recorded at several stages between days 6 and 14, using an isolated cord preparation (Landmesser and O'Donovan, 1984). Embryos were removed from the shell and decapitated. After evisceration, the animal was superfused with oxygenated Tyrode solution and maintained at $28-30^{\circ} \mathrm{C}$. The ventral surface of the spinal cord was exposed by laminectomy, and the ventral roots and hindlimb muscle nerves isolated for recording.

Neural activity was recorded from the sartorius and caudilioflexorius muscle nerves and also from the ventral roots. These antagonist motor nerves were chosen because their activity during normal and treadmill locomotion has been documented and shown to have a comparatively uncomplicated pattern of alternation (Landmesser, 1978; Jacobson and Hollyday, 1982). We have previously shown that by stage 36 these muscles display the mature pattern of alternating activity both in ovo and in vitro (Landmesser and O'Donovan, 1984). Recordings were made from muscle nerves or ventral roots during episodes of spontaneous or evoked motor activity. Data were obtained from spontaneous episodes at all stages examined, but in 3 of the older embryos (stages 34-36) motor activity was evoked by a single stimulus to the thoracic cord (Landmesser and O'Donovan, 1984).

Ventral root recording. Differential recordings were obtained from the cut central ends of ventral roots LS1 or LS2 using a suction electrode referenced to an indifferent electrode in the bath. The recording electrode was connected to the input of a high-gain DC amplifier via chlorided silver wire. Signals were amplified $(\times 1000)$ using a wide bandwidth (DC-5 kHz), which allowed slow ventral root potentials to be recorded, in addition to propagated spike activity. In most experiments, ventral root spike activity was also recorded, using a conventional $\mathrm{AC}$ amplifier with a bandwidth of $100 \mathrm{~Hz}-5 \mathrm{kHz}$. Signals were recorded on an FM tape recorder (Vetter Model D) and displayed on an electrostatic chart recorder (Gould ES 1000; frequency response DC-10 kHz) or a light beam oscillograph (Soltec Visigraph 5L; frequency response DC-1.5 $\mathrm{kHz}$ ). In some experiments the DC ventral root signal was filtered to separate propagated spike activity from the slower ventral root potentials. The slow-wave activity (filtered at DC-100 Hz) was usually of much larger amplitude than the spike activity (filtered at $100 \mathrm{~Hz}$ to 5 $\mathrm{kHz}$ ), which had the benefit that low-pass filtering did not distort the trajectory of the slow potentials by integrating the spike activity (see Fig. 1). Ventral root slow potentials recorded in this manner correspond closely (in form and time course) to the membrane potential trajectory recorded intracellularly from motoneurons, both in the chick embryo (O'Donovan, 1986b, 1987) and in other species (Luscher et al., 1979; Brink et al., 1983; Frank and Westerfield, 1983).

An important consideration in making these recordings was the extent to which medial motoneurons innervating trunk musculature might contribute to the spike and slow-wave activity. This is a possibility because the ventral roots contain axons from motoneurons originating from the medial motor column, in addition to the more numerous lateral motor column axons (Chu-Wang and Oppenheim, 1978). However, contamination of the ventral root recordings by potentials generated in medial motoneurons is unlikely in these experiments. First, only a minority of axons in the ventral roots originate from medial column motoneurons (Chu-Wang and Oppenheim, 1978), so that their contribution to ventral root potentials would be small. Second, the axons of medial motoneurons do not extend very far into the ventral root in young embryos (Tosney and Landmesser, 1985) and would probably not be sucked into the recording electrode, which was located on the distal end of the root. Both of these suppositions are supported by the observation that very little ventral root discharge was recorded at stage 26 , despite the fact that medial motoneurons were firing during episodes of motor activity, as revealed by spontaneous contractions of trunk muscles. Finally, as soon as motor nerve activity could be recorded (stage 29), its form was identical to that recorded in the ventral roots.

Muscle nerve recording. Neural activity was recorded from the cut central end of the sartorius and caudilioflexorius muscle nerves after they had been pulled into tight-fitting suction electrodes. Signals were amplified with a bandwidth of $50 \mathrm{~Hz}-5 \mathrm{kHz}$ and stored on magnetic tape for subsequent analysis. The pattern of motor discharge was quantified by constructing histograms of the probability of activity in a single cycle (see Landmesser and O'Donovan, 1984). For this purpose, the duration of sartorius and caudilioflexorius activity was measured in each cycle relative to the end of a brief discharge in the sartorius nerve (the "synchronous discharge") that initiated each cycle. Neural discharge was measured in $100 \mathrm{msec}$ intervals and expressed as a probability by computing the relative frequency of activation over many cycles. The probability measures for individual experiments were averaged, and the mean and standard deviation plotted for the duration of a complete cycle.

\section{Results}

Spontaneous motor activity generated by the isolated spinal cord consisted of recurring episodes during which motoneurons discharged cyclically. Both the frequency of the episodes and the number of cycles in each episode depended primarily on the age of the embryo, although the state of the preparation appeared to be important also. For example, towards the end of the experiment (usually $12 \mathrm{hr}$ after the initial dissection), the motor responses tended to occur less frequently and with fewer cycles. Furthermore, some of the older embryos were not spontaneously active, presumably because they were more susceptible to anoxia than were younger animals. Episodes were most frequent in the youngest embryos, recurring at a maximum rate of about $1-2 /$ min, whereas in older animals the maximum rate declined to one every 4-5 $\mathrm{min}$. In the youngest embryos (stage 26), each episode consisted of a single cycle of activity. With further development the number of cycles in each episode increased, so that by stages 36-40, an episode could last 30-40 sec and comprise up to 12 cycles (see Fig. 3).

\section{Developmental changes in ventral root activity}

Figure 2 illustrates the developmental change in ventral root potentials and neural discharge recorded during episodes of motor activity. Each cycle of spontaneous motor activity was associated with a positive, monophasic ventral root potential with a rapid rising phase and a slower decline. In older embryos (days 11 and 14), the first few cycles of activity could recur rapidly enough to result in temporal summation of successive ventral root potentials (Fig. 2, $C, D$ ). The duration of the potential in each cycle was similar in embryos at stage 29 and older, but in the stage 26 embryos $(n=2)$, the potential was significantly shorter and exhibited no plateau phase (Fig. $2 A$ ).

The onset of the ventral root potential was accompanied by a brief discharge, although in stage 26 embryos the discharge was barely detectable. This initial discharge is probably equivalent to the brief burst that initiates motor activity in ovo, called the "synchronous discharge" (Landmesser and O'Donovan, 1984) or the initiating discharge (Provine, 1972, 1973). The synchronous discharge was only observed when a rapid change in the ventral root potential occurred. For example, during temporal summation of ventral root potentials, cycle onset was not associated with a brief initial burst (see Fig. 2, C, D).

In contrast to the limited developmental changes in the form and time course of ventral root potentials, the pattern of motor discharge did change substantially during development. At day 6 (stage 26), ventral root discharge was barely resolvable, whereas a day later a prominent burst initiated each cycle. At day 7 (stage 29) motoneuron discharge was still restricted to the early part of the cycle despite the fact that the ventral root potential remained elevated for 1-2 sec during each cycle. In older embryos a second discharge followed the synchronous discharge after a brief delay (Figs. 2, 3C). 

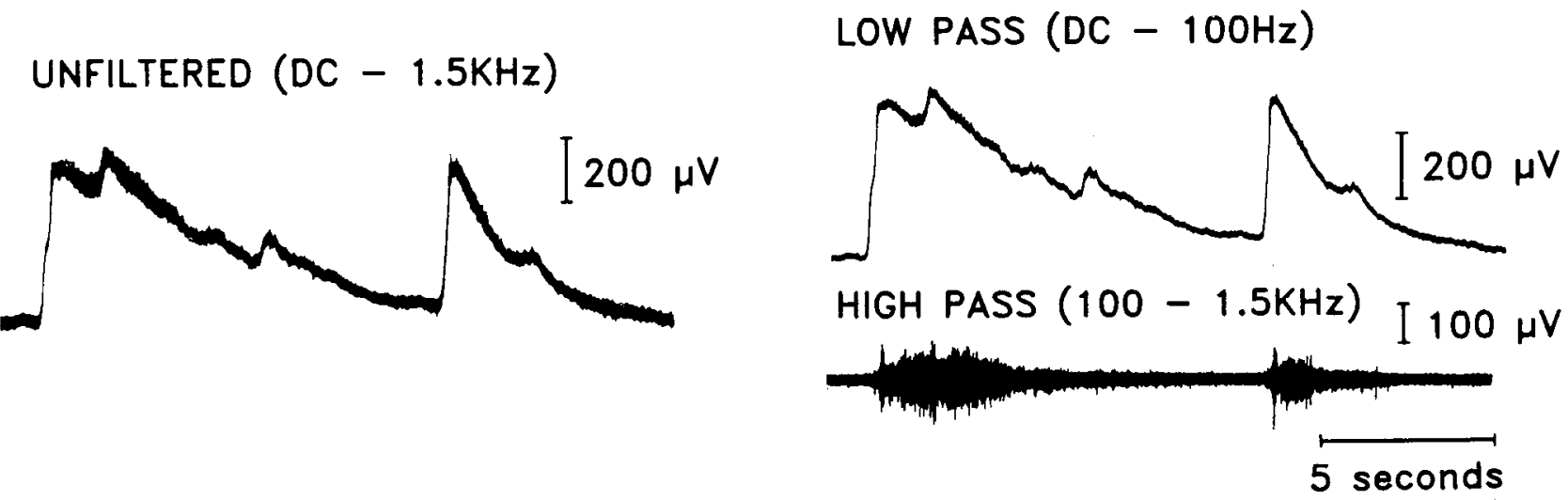

Figure 1. Example of ventral root potentials recorded from LS2 in a 14-d-old embryo. The ventral root records were obtained with a suction electrode tightly applied to the cut central end of the ventral root and referenced to an indifferent electrode within the bath. The recording was initially made with a high bandwidth (left panel, unfiltered) so that the signal is composed of propagated spikes superimposed on slow-wave activity. Because the frequency content of the spike and slow wave are so different, they can be separated by filtering. As shown in the right panel, the time course and form of the low-pass (DC, $100 \mathrm{~Hz}$ ) signal is identical to the unfiltered signal. In this experiment, the propagated spike activity (highpass; $100 \mathrm{~Hz}-1.5 \mathrm{kHz}$ ) was recorded using a conventional $\mathrm{AC}$ amplifier that was also connected to the ventral root electrode.

This pattern of motor development is strikingly similar to that obtained by Provine (1972, 1973), who characterized the development of motor activity in ovo by recording polyneuronal burst activity within the spinal cord. Provine reported that the earliest spinal neural activity in ovo consisted of brief, low- amplitude bursts similar to those illustrated in Figures 2, $A, B$ (compared to fig. 3 in Provine, 1972). At day 7 in ovo, a second burst appeared in each cycle, which was referred to as the afterdischarge and which is similar to the delayed discharge first seen at stage 31 in the isolated cord (see below).
A $6 \mathrm{DAY}$

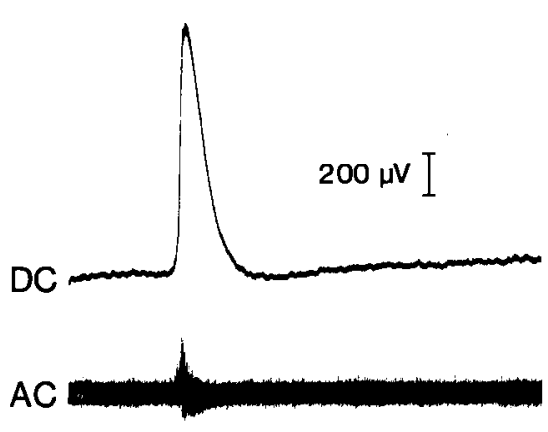

11 DAY

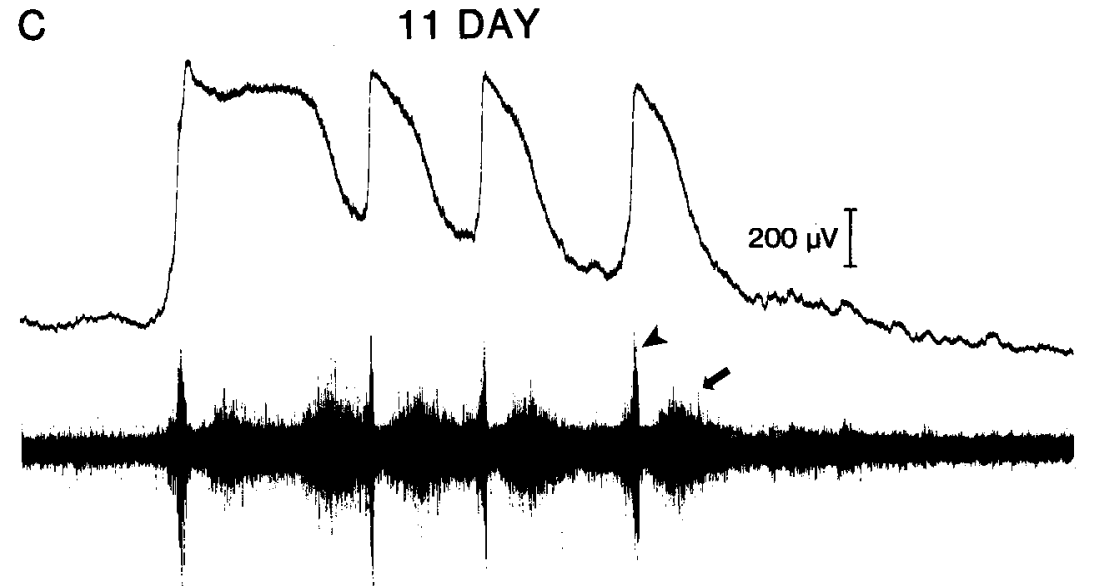

D $\quad 14$ DAY
B

7 DAY
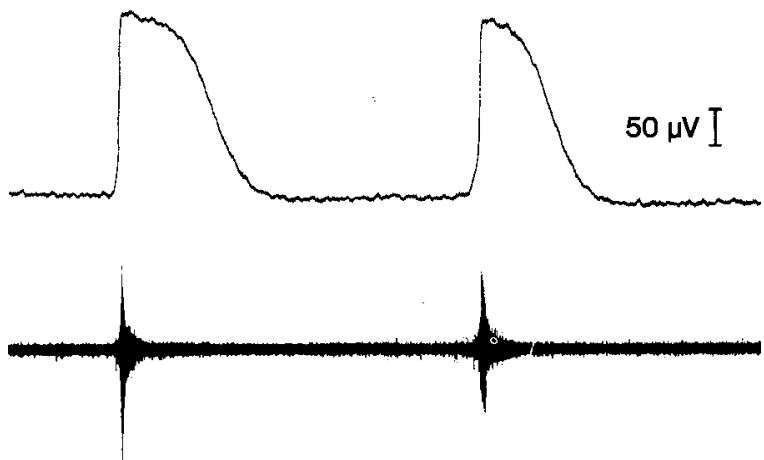
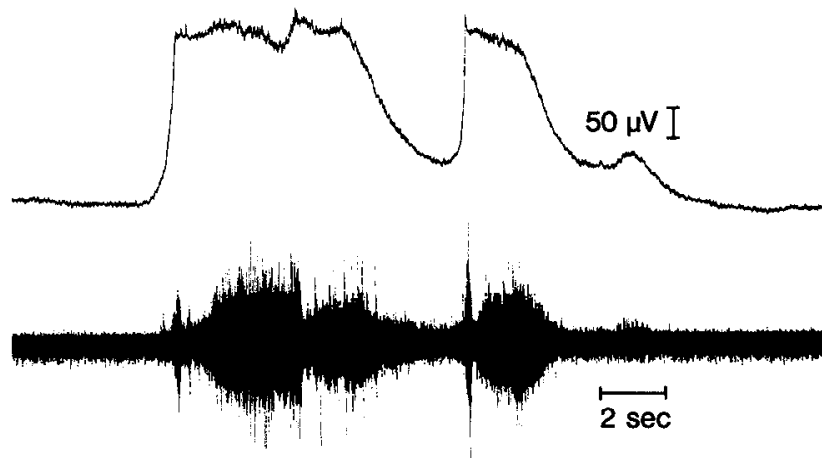

Figure 2. Developmental changes in spontaneous ventral root activity (LS1 or LS2). The recordings were originally amplified between DC and $10 \mathrm{kHz}$ and then low-pass-filtered $(\mathrm{DC}-100 \mathrm{~Hz}$ ) in the upper traces (labeled $D C$ ) to separate the slow-wave activity. AC records of spike activity were obtained either by separately amplifying the electrode signal using an AC amplifier or by high-pass-filtering the DC signal (100 Hz-5 kHz). The arrowhead identifies the "synchronous" component of motoneuron discharge, and the arrow the delayed component. 
A

STAGE 30
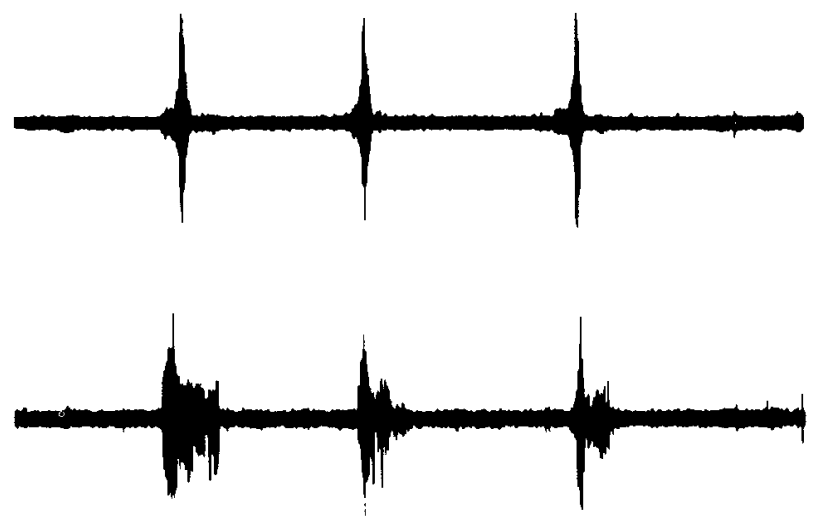

B STAGE 31
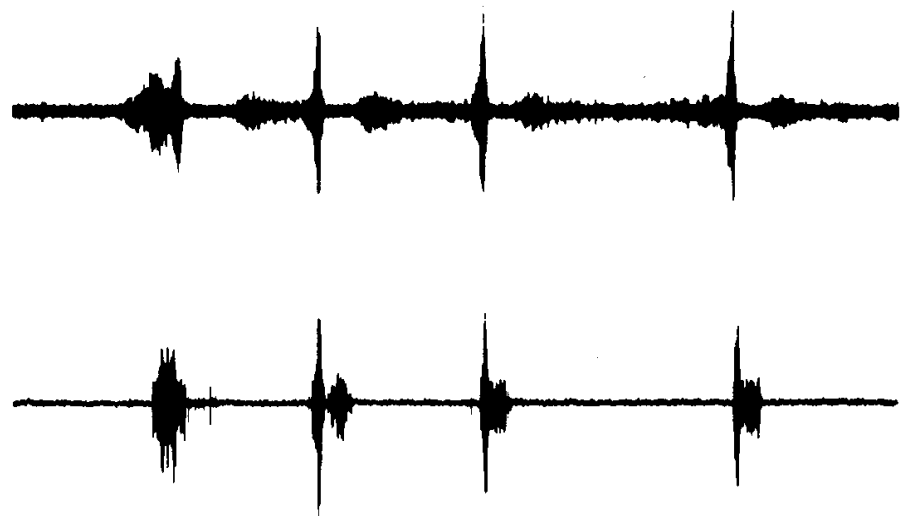

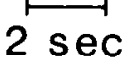
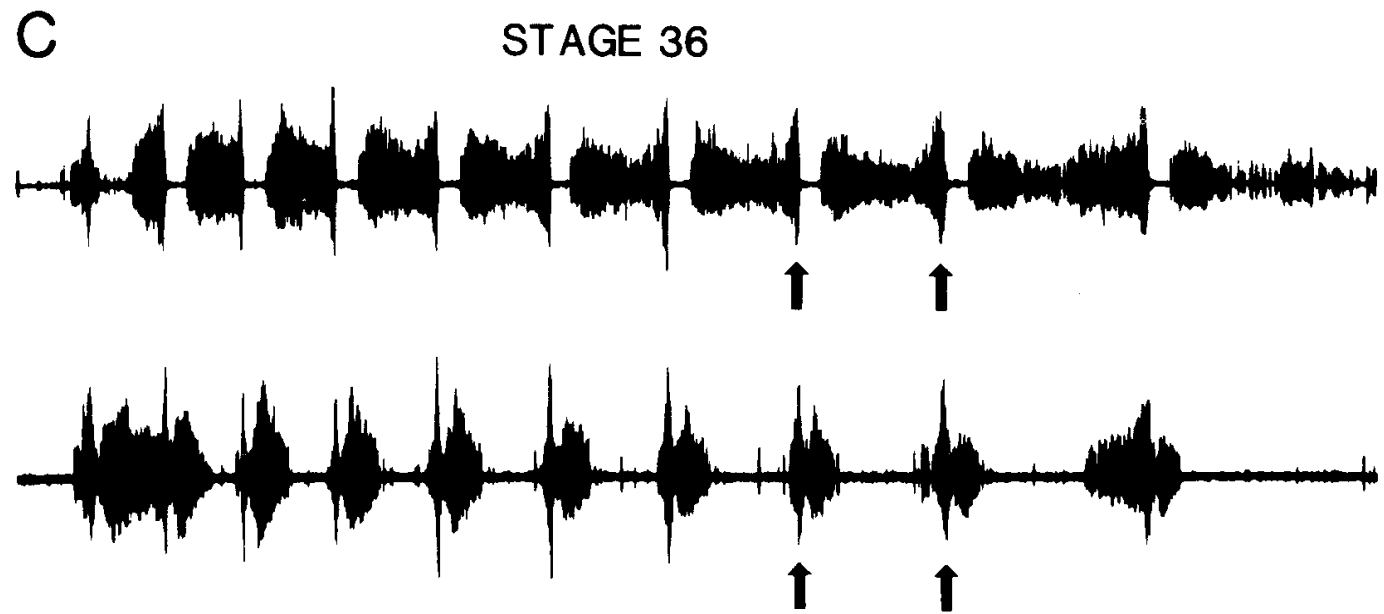

Figure 3. Development of antagonist motor activity. Each pair of records includes an extracellular neurogram recorded from the flexor sartorius (upper records) and the extensor caudilioflexorius muscle nerves during an episode of spontaneous motor activity. The arrows in $C$ identify the synchronous discharge in both neurograms.

\section{Developmental changes in caudilioflexorius and sartorius} neural activity

Phasing of neural activity. The developmental changes in muscle nerve activity (Fig. 3) were similar to those described for the ventral roots (Fig. 2). Early in development (at stages 29-30), activity in both the sartorius and the caudilioflexorius muscle nerves was dominated by the synchronous discharge that ini- tiated each cycle. By stage 31, a second, delayed discharge appeared in each cycle of sartorius activity (Fig. $3 B$ ). The delayed sartorius discharge began approximately $0.7 \mathrm{sec}$ after the synchronous discharge, and coincided with the termination of the caudilioflexorius burst. By stage 36, the amplitude of the second discharge in both muscle nerves had intensified and the duration of sartorius activity had lengthened, with the result that the antagonist motoneurons alternated their discharge. 

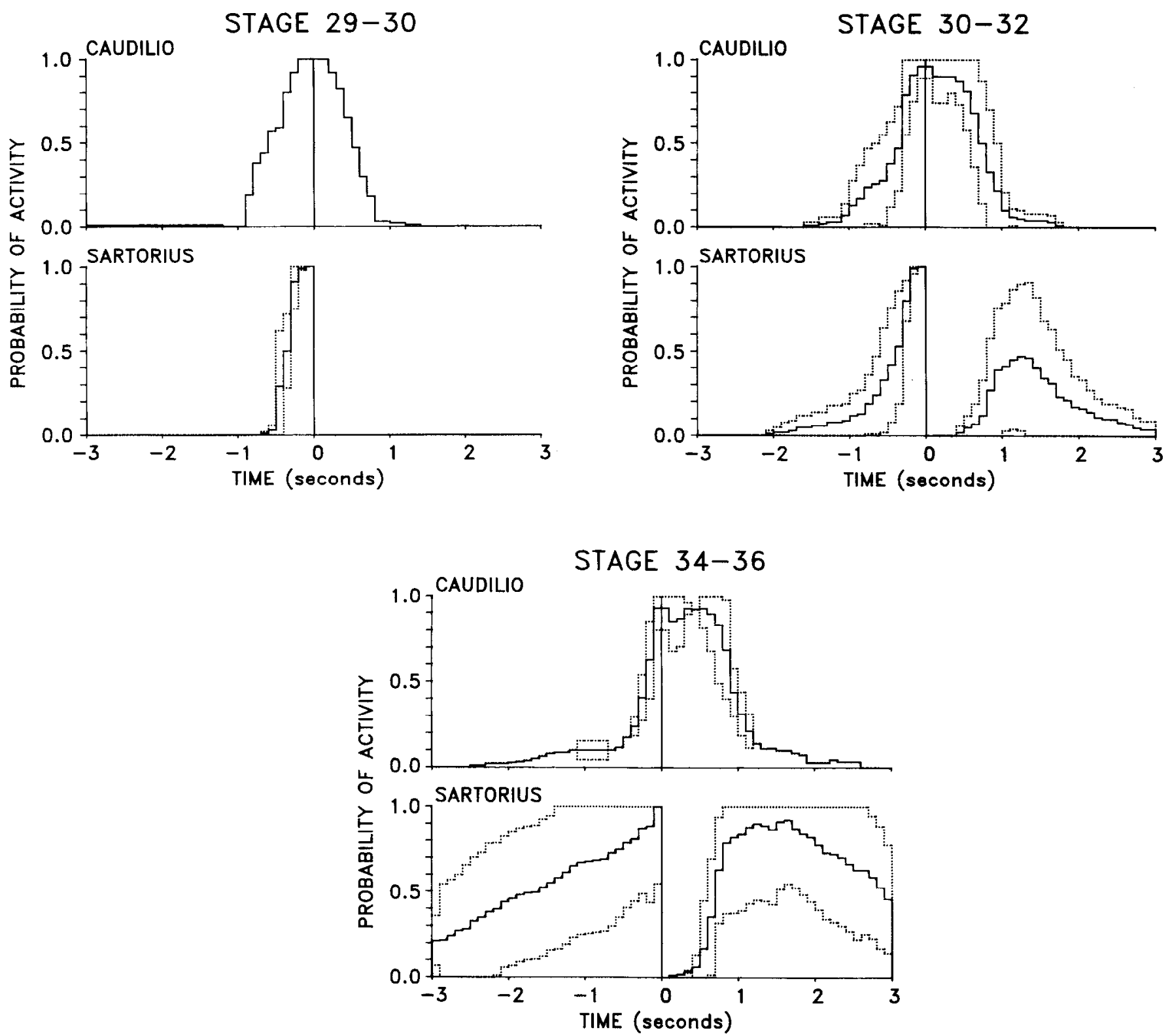

Figure 4. Histograms illustrating the developmental changes in a single cycle of sartorius and caudilioflexorius motor activity. The probability histograms were constructed for a single cycle of activity referenced to the end of the synchronous discharge in the sartorius neurogram (see text for further details). The solid lines are average probabilities of activity and the interrupted lines the means \pm 1 SD. Each plot was constructed from many cycles from $2-5$ embryos.

The developmental changes in the activation pattern of the 2 muscle nerves were quantified by constructing histograms of their activity during a single cycle (Fig. 4). These histograms were generated from a large number of cycles from 3-5 embryos at each age (with the exception of caudilioflexorius at stage 30 ; $n=2$ ), and display the average probability of activity $( \pm \mathrm{SD})$ during a single cycle, defined with reference to the end of the synchronous discharge in the sartorius neurogram (see Materials and Methods).

At stages 29-30, the sartorius activity was concentrated in a single peak corresponding to the synchronous discharge. By contrast, the caudilioflexorius histogram was broader and was distributed approximately symmetrically about the reference point in sartorius. The second component in the sartorius discharge first appeared between stages 30 and 32 and was quite variable at this age. In some cycles the discharge was absent, which accounts for the large standard deviation associated with the mean activity (see Fig. 4). At stage 32, a greater proportion of caudilioflexorius activity occurred after the sartorius reference point than had at stage 30 . This shift was maintained during development, so that by stages $34-36$ most caudilioflexorius activity followed the sartorius reference point and coincided with the silent period in sartorius activity.

The precision of alternation improved between stages 32 and 36 , primarily because caudilioflexorius activity coincided more completely with the silent period in sartorius (see Fig. 4). Because the duration of caudilioflexorius burst activity changed little with development (Fig. 6), the increased precision of alternation suggested a change in the temporal coupling of sartorius and caudilioflexorius activity. The developmental changes in coupling were documented by measuring the fraction of caudilioflexorius activity that occurred after the sartorius synchro- 


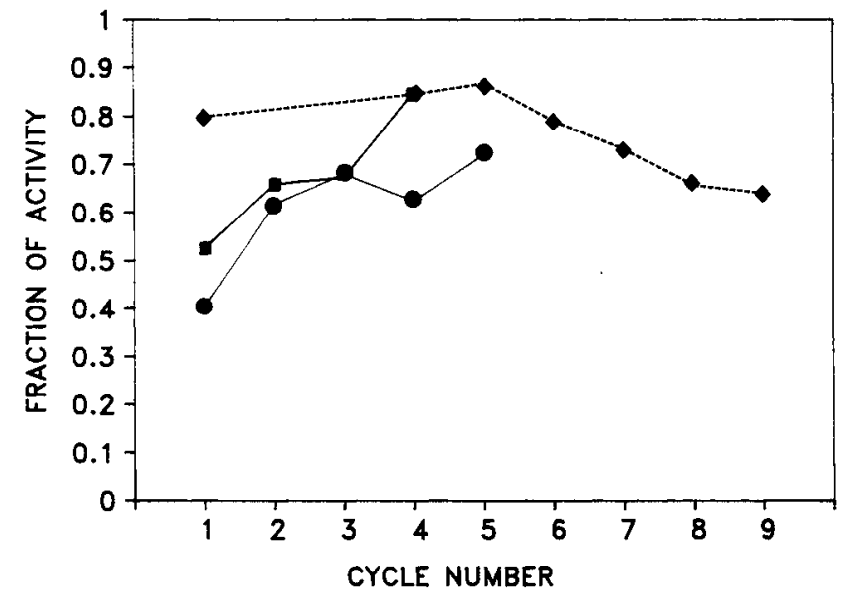

Figure 5. Changes in the relative timing of the caudilioflexorius discharge with respect to the synchronous discharge in sartorius. The fraction of the caudilioflexorius burst that occurs after the sartorius synchronous discharge (fraction of activity) has been plotted for each cycle of an episode at 3 different developmental stages (cycles 2 and 3 have been excluded from the stage 34-36 plot; see text). Data points are the averages of many cycles from 2-5 embryos. $--\infty$. Stages 34-36; $\longrightarrow$, stages $31-32 ; \square-$ stage 30 . nous discharge at several stages of development (Fig. 5).

Figure 5 shows that the fraction of extensor activity occurring after the sartorius synchronous discharge varies in successive cycles in an age-dependent manner. In the youngest embryos (stages 30-32), the onset of caudilioflexorius activity shifted to progressively later times during successive cycles. For example, in the first cycle about $50 \%$ of the caudilioflexorius burst preceded the sartorius synchronous discharge, whereas in later cycles a smaller fraction preceded the reference point. In older embryos (stages 34-36), the onset of flexor and extensor activity had become more synchronous, although some changes in coupling occurred towards the end of an episode (see Fig. 5).

Duration of burst activity. In Figure 6, the duration of caudilioflexorius activity occurring after the synchronous discharge (filled circles, Fig. 6) has been plotted together with the total duration of caudilioflexorius activity in each cycle (rectangles, Fig. 6). The results reveal that the duration of caudilioflexorius activity in each cycle does not change substantially between stages 30-36, with the exception of the first few cycles in older embryos (see below). At stages 30-32, the duration of activity in each cycle was similar, falling from a maximum of $1.12 \mathrm{sec}$ in the first cycle to reach a minimum of approximately $0.9 \mathrm{sec}$ in later cycles (range, $0.85-0.94 \mathrm{sec}$ ). The tendency for initial
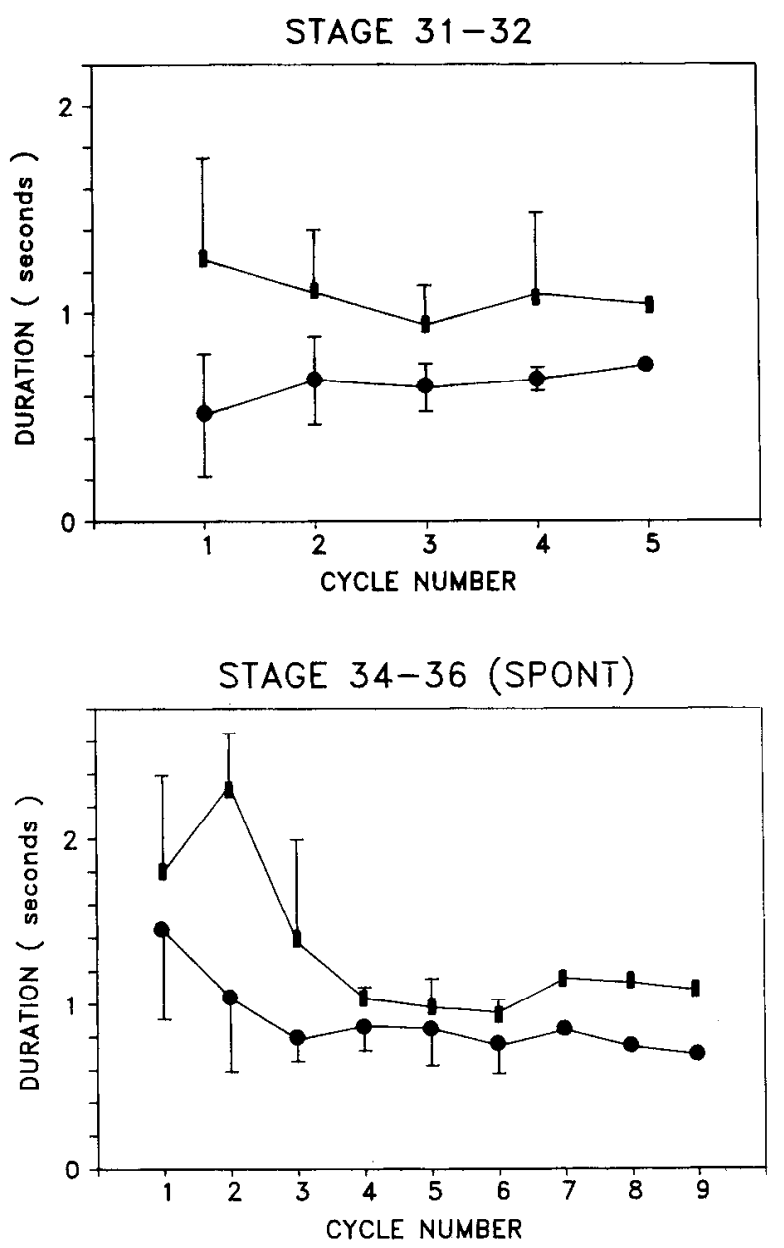

Figure 6. Changes in the duration of caudilioflexorius activity during a burst episode. The filled rectangles represent the duration of a single burst of caudilioflexorius activity, and the filled circles the duration of caudilioflexorius activity occurring after the end of the synchronous discharge in sartorius. At stages 34-36, data have been plotted for cvoked and spontaneous bursts together (stage 34-36) and for spontaneous episodes only (stage 34-36 SPON). Points are the averages \pm SDs of many cycles from 2-5 embryos. 

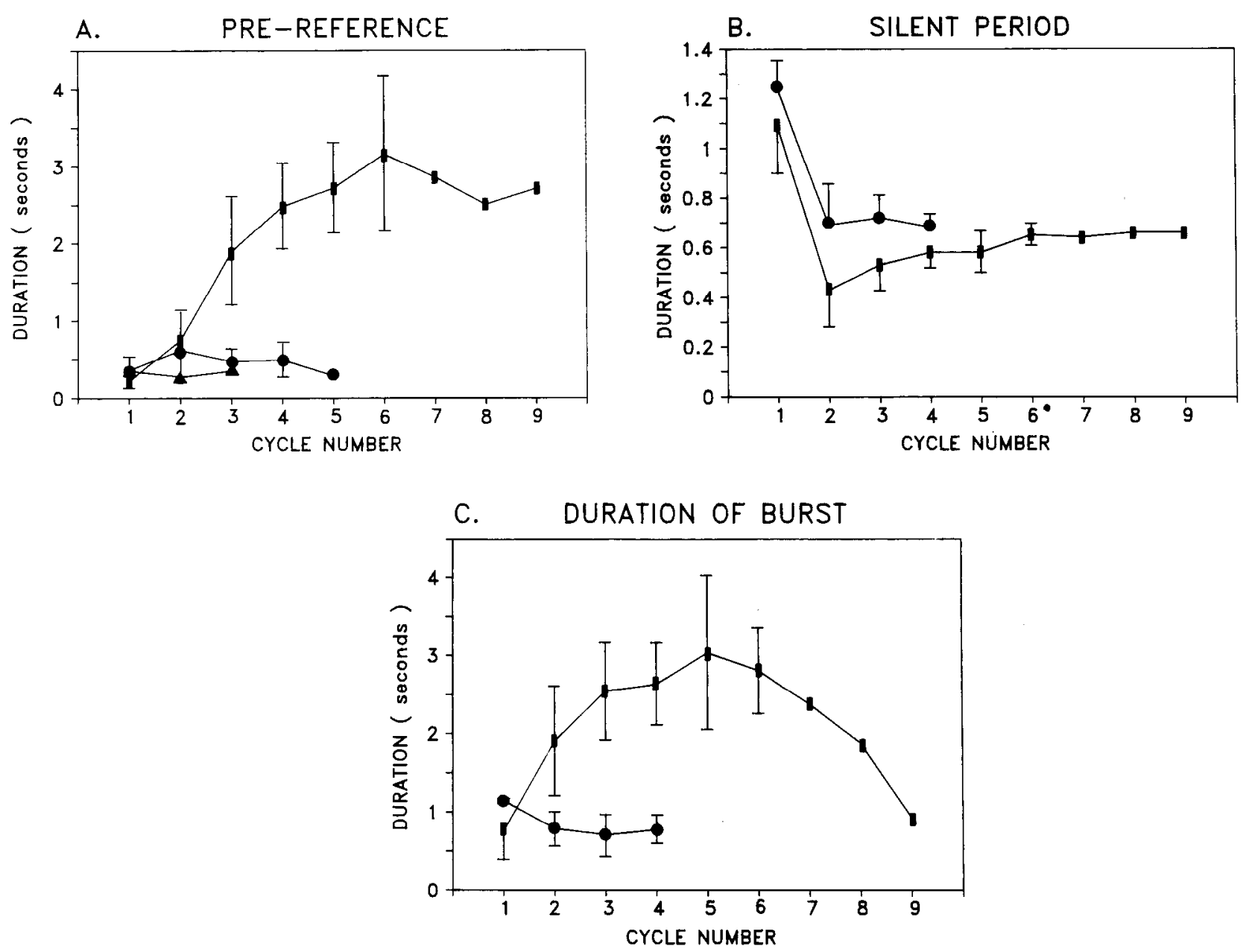

Figure 7. Changes in sartorius burst parameters during motor activity at 3 developmental stages. $\mathbf{\Delta}$, Stages 29-30; $\mathbf{0}$, stages $30-32$; $\mathbf{1}$, stages 34 36. Data points are the means $( \pm \mathrm{SD})$ from 3-5 embryos at each age.

bursts to be longer was even more marked in older embryos, in part because fusion of successive cycles occurred (see Figs. 2, 3). In stages 34-36, embryos' burst duration fell after the first 3 cycles to plateau at about $1 \mathrm{sec}$ (range, $0.97-1.08 \mathrm{sec}$ ), which was close to the burst duration in younger embryos. Although the duration of caudilioflexorius bursts did not change much with development, the intensity of the second discharge increased progressively between stages 30 and 36 (as shown in Figs. 3 and 4).

In contrast to the limited developmental changes in the duration of caudilioflexorius activity, the duration of the second component of the sartorius discharge (plotted as duration of burst in Fig. 7C) increased substantially during development. At stage 32 , the duration of the second component fell from a maximum in the first cycle $(1.15 \pm 0.04 \mathrm{sec})$ to stabilize at $0.7-$ $0.8 \mathrm{sec}$ in later cycles (range, $0.71-0.78 \mathrm{sec}$ ). By stage 36 , the duration of this component had lengthened substantially, reaching $3 \mathrm{sec}$ in some cycles (see Fig. 7C). In many cycles the synchronous discharge abruptly terminated the discharge of the previous cycle (see Fig. $3 \mathrm{C}$ ). As a result, the activity preceding the end of the synchronous discharge (plotted as preference in Fig. $7 A$ ) could not be distinguished from the second component of the previous cycle. In younger embryos in which successive cycles were distinct, the duration of sartorius activity preceding the end of the synchronous discharge was comparatively stable, ranging from 0.28 to $0.63 \mathrm{sec}$ (Fig. $7 A$ ).

Figure 7 also illustrates the developmental changes in the duration of the sartorius silent period between the end of the synchronous discharge and the onset of the second discharge. At all ages the silent period was longest in the first cycle (1.24 \pm $0.11 \mathrm{sec}$ at stages $31-32 ; 1.15 \pm 0.04 \mathrm{sec}$ at stages $34-36$ ), and fell sharply in subsequent cycles. At stages $30-32$, the silent period stabilized at approximately $0.7 \mathrm{sec}(0.68-0.72 \mathrm{sec})$ in later cycles, whereas in the older embryos it lengthened from a minimum in the second cycle $(0.43 \pm 0.15 \mathrm{sec})$ to reach a maximum at the end of the episode $(0.66 \mathrm{sec})$.

\section{Discussion}

In this study we have documented developmental changes in the pattern of spontaneous motor activity generated by an isolated preparation of the chick spinal cord. The results demonstrate that the neural output from motoneurons progressively increases throughout development, and that antagonist alternation appears at stage 31 , confirming previous in ovo studies by Bekoff (1976) and Provine (1972, 1973). The results also indicate that the development of alternation between caudilioflexorius and sartorius is primarily associated with changes in the activation pattern of sartorius motoneurons. 
In the youngest embryos (stage 26), motoneuron discharge was barely detectable in some cycles despite the presence of large ventral root potentials. Even at stage 29, motoneuron discharge was restricted to the rising phase of the ventral root potential. Only later, at stage 30 , did significant spike activity occur later in the cycle.

This pattern of development is very similar to the sequence of motor development in ovo obtained by Provine (1972, 1973) using microelectrode recordings from lumbosacral spinal neurons. In ovo recordings revealed only very low-level activity at $5 \mathrm{~d}$, whereas by $6 \mathrm{~d}$ burst activity consisted of brief, intense discharges. With further development a second, more prolonged, discharge followed the initial discharge (Provine, 1972). Although motoneurons were not specifically identified in Provine's studies, it is likely that his recordings included motoneurons that are among the largest ventrally located spinal neurons. The similarities between in vitro and in ovo motor development strongly suggest that mechanisms responsible for motor activity in the isolated cord are similar, if not identical, to those responsible for motor activity in ovo. Moreover, they also imply that the low level of motoneuron activity at stage 26 in vitro is not an artifact of the isolated cord preparation, because ncural activity in ovo is also low at this age.

One mechanism that may account for the low level of neural activity in young embryos (stage 26) is that the level of motoneuron synaptic drive is subthreshold for firing. Compatible with this idea is the observation that ventral root potentials were briefer at stage 26 than at any other time in development. However, this explanation is less satisfactory at stage 29 , when motoneurons only fired at the beginning of the cycle, although the ventral root potential, and presumably motoneuron depolarization, remained elevated for 1-2 sec. The absence of delayed discharge at stage 29 could arise if motoneurons were incapable of repetitive firing. According to this idea, the delayed components of the cycle would appear concomitantly with the capacity of motoneurons to fire repetitively. Axonal excitability could be tested by stimulating ventral roots and recording from muscle nerves, but the repetitive firing properties of motoneuron cell bodies would be more difficult to examine because intracellular recording might not be possible in very young embryos. One approach would be to monitor the development of motoneuron excitability in culture, as has been done for several neuronal types (see Spitzer, 1979). Recently O'Brien and Fischbach (1986) exploited this approach to show that motoneurons cultured from $5 \mathrm{~d}$ chicks are capable of generating action potentials, although the repetitive firing behavior of motoneurons was not described.

In the youngest embryos (stage 26), limb movements did not accompany ventral root activity and could not be elicited by direct stimulation of the lateral motor column. At these early stages, spontaneous movements were limited to trunk muscles. At stage 26 in the chick, the hindlimb muscle masses have not cleaved into separate muscles, and although axons are in the limb, they have not invaded the muscle masses (Tosney and Landmesser, 1985). Landmesser and Morris (1975) reported that spinal nerve stimulation first evoked movement in the hindlimb muscle masses at stages $27-28$, suggesting that muscle innervation becomes functional at this time. Therefore, the presence of large ventral root potentials in stage 26 embryos raises the possibility that synaptic inputs to hindlimb motoneurons are operational prior to the establishment of functional muscle innervation. The appearance of synaptic drive prior to moto- neuron discharge is also seen during the development of other species. For instance, in the bullfrog tadpole, rhythmic motoneuron depolarizations precede motoneuron discharge and can be detected in hindlimb motoneurons before innervation of the limb (Stehouwer and Farel, 1983, 1985).

Between stages 26 and 31, the ventral root potential lengthened and motor discharge intensified with the first appearance of alternating motor activity. Over this period, motoneurons are innervating their target muscles, raising the possibility that muscle innervation may be causal to some of the changes in motor activity. Alternatively, the development of motor activity may be important for axonal guidance or synapse formation with muscle. While activity has not been implicated in the innervation of individual limb muscles (see Oppenheim, 1981; Landmesser and Szente, 1986), it could be involved in the innervation of particular myotube classes or of particular regions within the muscle.

In older embryos, a second phase of discharge occurred in each cycle. The appearance of the second discharge cannot simply be attributed to a lengthening of depolarizing synaptic drive, because the duration and form of ventral root potentials were similar from stage 29 to stage 40 . While we cannot exclude some developmental changes in the synaptic drive to individual flexor and extensor motoneurons, these observations raise the possibility that motoneuron membrane properties may play a role in the maturation of motor activity patterns. However, definitive resolution of this issue must await a comprehensive cellular analysis of the mechanisms underlying patterned motor activity; this is now feasible, using the isolated cord preparation (see O'Donovan, 1987).

Developmental changes in the organization and output of interneuronal circuits must also contribute to the maturation of motor output. The number of cycles in each episode progressively increased from a minimum of one cycle at stage 26 to a maximum of 10-12 cycles later in development. Recent observations in the chick embryo (and in other species) suggest that interneurons releasing excitatory amino acids may mediate some aspects of motoneuron excitation during motor activity (Dale and Roberts, 1985; Barry and O'Donovan, 1985; Dale and Grillner, 1986). Barry and O'Donovan (1985, and unpublished observations) have shown that the number of cycles in an episode can be increased by bath-application of $N$-methyl-DL-aspartate (NMDA) and reduced by the NMDA antagonist DL-2-amino5-phosphonovaleric acid (APV). It is possible, therefore, that developmental changes in these neurotransmitter systems could be involved in the maturation of motor activity-an hypothesis that we are currently investigating.

\section{References}

Barry, M., and M. J. O'Donovan (1985) Pharmacological activation of locomotor activity in the developing spinal cord of the chick embryo. Soc. Neurosci. Abstr. 11: 259.

Bekoff, A. (1976) Ontogeny of leg motor output in the chick embryo: A neural analysis. Brain Res. 106: 271-291.

Bekoff, A., P. S. G. Stein, and V. Hamburger (1975) Coordinated motor output in the hindlimb of the 7-day-old chick embryo. Proc. Natl. Acad. Sci. USA 72: 1245-1248.

Brink, E., P. J. Harrison, E. Jankowska, D. A. McCrea, and B. Skoog (1983) Post-synaptic potentials in a population of motoneurons following activity of single interneurons in the cat. J. Physiol. (Lond.) 343: 341-359.

Chu-Wang, I.-Wu., and R. W. Oppenheim (1978) Cell death of motoneurons in the chick embryo spinal cord. II. A quantitative and qualitative analysis of degeneration in the ventral root, including 
evidence for axon outgrowth and limb innervation prior to cell death. J. Comp. Neurol. 177: 59-86.

Dale, N., and S. Grillner (1986) Dual component synaptic potentials in the lamprey mediated by excitatory amino acid receptors. J. Neurosci. 6: $2653-2661$.

Dale, N., and A. Roberts (1985) Dual component amino acid mediated synaptic potentials: Excitatory drive for swimming in xenopus embryos. J. Physiol. 363: 35-59.

Eide, A. H., J. K. S. Jansen, and R. R. Ribchester (1982) The effect of lesions in the neural crest on the formation of synaptic connection in the embryonic chick spinal cord. J. Physiol. (Lond.) 324: 453-478.

Frank, E., and M. Westerfield (1983) Development of sensory-motor synapses in the spinal cord of the frog. J. Physiol. (Lond.) 343: 583610.

Grillner, S. (1981) Control of locomotion in bipeds, tetrapods and fish. In Handbook of Physiology, vol. II, sec. I: Motor Control, pt. 2, V. B. Brooks, eds., pp. 1179-1236, American Physiological Society, Bethesda, MD.

Ilamburger, V. (1976) The developmental history of the motoneuron. Neurosci. Res. Bull. 15: 1-37.

Jacobson, R. D., and M. Hollyday (1982) A behavioral and electromyographic study of walking in the chick. J. Neurophysiol. 48: 238256.

Kahn, J. A., and A. Roberts (1982) Experiments on the central pattern generator for swimming in amphibian and embryos. Phil. Trans. R. Soc. Lond. [Biol.] 296: 229-243.

Landmesser, L. (1976) The development of neural circuits in the limb moving segments of the spinal cord. In Neural Control of Locomotion, R. M. Herman, S. Grillner, P. S. G. Stein, and D. G. Stuart, eds., pp. 707-733, Plenum, NY.

Landmesser, L. (1978) The distribution of motoneurons supplying chick hindlimb muscles. J. Physiol. (Lond.) 284: 371-389.

Landmesser, L. (1980) The generation of neuromuscular spccificity. Annu. Rev. Neurosci. 3: 279-302.

Landmesser, L., and D. G. Morris (1975) The development of functional innervation in the hindlimb of the chick embryo. J. Physiol. (Lond.) 249: 301-326.

Landmesser, L. T., and M. J. O'Donovan (1984) Activation patterns of embryonic chick hindlimb muscles recorded in ovo and in an isolated spinal cord preparation. J. Physiol. (Lond.) 347: 189-204.

Landmesser, L. T., and M. Szente (1986) Activation patterns of embryonic chick hindlimb muscles following blockade of activity and motoneurone cell death. J. Physiol. (Lond.) 380: 157-174.

Luscher, H.-R., P. Ruenzel, E. Fetz, and E. Henneman (1979) Postsynaptic population potentials recorded from ventral roots perfused with isotonic sucrose: Connections of groups Ia and II spindle afferent fibers with large populations of motoncurons. J. Neurophysiol. 42: $1146-1164$.

O'Brien, R. J., and G. D. Fischbach (1986) Isolation of embryonic chick motoneurons and their survival in vitro. J. Neurosci. 6: 32653274

O'Donovan, M. J. (1986a) Experimental analysis of motor development in the chick embryo. In Neurobiology of Vertebrate Locomotion (Wenner-Gren Symposium Series), S. Grillner, P. Stein, D. Stuart, H. Forssgerg, and R. Herman, eds., pp. 415-432, Macmillan, London. O'Donovan, M. J. (1986b) Intracellular recordings from embryonic motoneurons during evoked and spontaneous motor activity. Soc. Neurosci. Abstr. 12: 1117.

O'Donovan, M. J. (1987) Developmental approaches to the analysis of vertebrate central pattern generators. J. Neurosci. Methods (in press).

Okada, N., and R. W. Oppenheim (1985) The onset and development of descending pathways to the spinal cord in the chick embryo. J. Comp. Neurol. 232: 143-161.

Oppenheim, R. (1981) Cell death of motoneurons in the chick embryo spinal cord. Evidence on the role of cell death and neuromuscular function in the formation of specific connections. J. Neurosci. $1: 141-$ 151.

Provine, R. R. (1972) Ontogeny of bioelectric activity in the spinal cord of the chick embryo and its behavioral implications. Brain Res. 41: 365-378.

Provine, R. R. (1973) Neurophysiological aspects of behavior development in the chick embryo. In Behavioral Embryology, vol. 1, G. Gottlieb, ed., pp. 77-102, Academic, New York.

Ripley, K. L., and R. R. Provine (1972) Neural correlates of embryonic motility in the chick. Brain Res. 45: 127-134.

Soffe, S. R., and A. Roberts (1982) Activity of myotomal motoneurons during fictive swimming in frog embryos. J. Neurophysiol. 48: 12741278.

Spitzer, N. C. (1979) Ion channels in development. Annu. Rev. Neurosci. 2: 363-397.

Stehouwer, D. J., and P. B. Farel (1980) Central and peripheral controls of swimming in anuran larvae. Brain Res. 195: 323-335.

Stehouwer, D. J., and P. B. Farel (1983) Development of hind limb locomotor activity in the bullfrog (Rana catesbeiana) studied in vitro. Science 219: 516-518.

Stehouwer, D. J., and P. B. Farel (1985) Development of locomotor mechanisms in the frog. J. Neurophysiol. 53: 1453-1465.

Tosney, K. W., and L. T. Landmesser (1985) Growth cone morphology and trajectory in the lumbosacral region of the chick embryo. J. Neurosci. 5: 2345-2358.

Velumian, A. A. (1981) Intracellular recordings from chick motoneurons in the isolated perfused spinal cord. Brain Res. 229: 502-506.

Velumian, A. A. (1984) Direct evidence for postsynaptic inhibition in the embryonic chick spinal cord. Dev. Brain Res. 14: 229-239.

Velumian, A. A. (1985) Antidromic action potential in spinal motoneurons of the chick embryo. Neurophysiology $17: 58-64$. 